\title{
Shrinkage and microstructure evolution during sintering of cemented carbides with alternative binders
}

\author{
Zoé Roulon ${ }^{\mathrm{a}}$, Jean-Michel Missiaen ${ }^{\mathrm{b}}$, Sabine Lay ${ }^{\mathrm{c}}$
}

\author{
Univ. Grenoble Alpes \& CNRS, SIMAP, Grenoble INP, F-38000 Grenoble, France

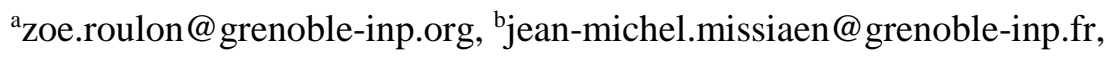 \\ 'sabine.lay@grenoble-inp.fr
}

\begin{abstract}
Keywords: Alternative binder, cemented carbides, sintering, shrinkage, microstructure evolution, densification mechanism.
\end{abstract}

Abstract

Cemented carbides are used in the cutting tools industry thanks to their exceptional mechanical properties. Manufactured by the powder metallurgy route, they are made of a hard WC phase with a ductile metallic binder, most commonly Co. Due to the lower availability of Co and its classification as carcenogenic material by the REACH European Regulation, new metallic binders have to be considered: Fe and Ni binders are investigated in this work. Because Co is the most common binder used in the hard metal industry for decades, there is still a lack of knowledge regarding the specific effect of alternative binders on shrinkage and microstructure evolution of cemented carbides.

The purpose of this work is to understand the effect of binder nature specifically, comparing classic Co binder used in the industry to pure $\mathrm{Fe}$ and $\mathrm{Ni}$ binder including the influence of carbon content. Shrinkage behaviour and microstructure evolution of $\mathrm{WC}-\mathrm{M}$ alloys $(\mathrm{M}=\mathrm{Co}, \mathrm{Ni}, \mathrm{Fe})$ are studied from dilatometry experiments as well as qualitative and quantitative microstructural characterisations. Solid state sintering is delayed to higher temperature for WC-Fe in comparison to WC-Co and WC-Ni alloys. Densification mechanisms are discussed in relation with dilatometry results, microstructural analyses, DFT calculations and a theoretical kinetic model from the literature.

1. Introduction 
Thanks to their exceptional hardness and wear resistance, cemented carbides have been used in the cutting tools industry since the 1920's as a substitute to the highly costly diamond tools [1]. Manufactured by the conventional powder metallurgy route [2], cemented carbides are made of tungsten carbide which provides a high hardness and of a ductile binder (cobalt in most case) which compensates for the brittle properties of WC [3]. With mechanical properties superior than other metallic alloys and with excellent wetting properties on tungsten carbide, Co is used as the most versatile binder in the hard metal industry. Nevertheless, since its classification as carcinogenic material by the European Regulation REACH [4] and its decreased availability due to new applications [5], extensive research has been performed to substitute Co with alternative binders [6]. With similar mechanical, physical and chemical properties [7], nickel whose supply risk is considered to be much lower than for Co and iron are the best candidates for an efficient binder in cemented carbides. Researches from thermodynamic data to mechanical properties on the WC-Fe-Ni-Co alloys intended to find the optimal Fe/Ni/Co metal proportion [8-10]. To look further, free-Co binder alloys with Fe/Ni matrix have been investigated [11,12], along with pure Fe or Ni metal binder [13] or Fe and Ni alloys with additional metals [14-16].

Although research has been conducted for a long time on the effect of the binder on final mechanical properties, there is still a lack of knowledge regarding the effect of binder composition on sintering and shrinkage of cemented carbides. Indeed, since Co is the most versatile binder used for almost a century, most of the investigations of the effect of binder composition on sintering have been conducted with this binder [3], in addition with the effect of carbon content, initial WC particle size, milling and sintering conditions [17]. According to these works, the binder spreads into the porosity of the WC powder compacts in the solid state by volume diffusion, resulting in particle rearrangement and shrinkage [18]. Densified clusters are formed by elimination of the smallest porosity, leaving large pores in between the clusters. When the melting temperature of the alloy is reached, liquid phase sintering begins. The liquid flows into the porosity under the action of capillary forces and solution-precipitation mechanisms induce shape changes and elimination of fine particles, which activates particle rearrangement and shrinkage. Shrinkage and densification in the solid state and in the presence of a liquid phase are both driven by the reduction of the interfacial energy.

In this work, densification and microstructure evolution are investigated for alternative binders, using WC$20 \mathrm{vol} \% \mathrm{M}(\mathrm{M}=\mathrm{Fe}, \mathrm{Ni}$ or $\mathrm{Co}$ ) alloys processed by the powder metallurgy route. The effect of carbon content is also studied. Dilatometric measurements are performed to study the shrinkage and characterization of the microstructure is deduced from SEM observations in the course of sintering. Image analysis is performed in order to provide quantitative information about evolution of the binder and pores phases.

\section{Experimental conditions}

High purity and fine raw materials (WC, Ni, Co, Fe) were used for the preparation of the alloys. From SEM observations, raw powders (Fig. 1) exhibit a mean size from 2 to $8 \mu \mathrm{m}$ approximately with a spherical shape 
for the iron powder, whereas nickel and cobalt powder show a "chain-like" structure with two scale particle sizes.


Fig. 1. FESEM images of a) $\mathrm{Co}$, b) $\mathrm{Ni}$, c) $\mathrm{Fe}$ and d) WC raw powders with addition of PEG.

WC powder, raw binder powder and $\mathrm{C}$ or $\mathrm{W}$ powder have been mixed in suitable proportion with lubricant (PEG) and milled together for approximately 43 hours with ethanol. Alcohol was then removed by spraydrying, and the powder was granulated in final spherical particles of approximately 5 to $30 \mu \mathrm{m}$ diameter size. $3 \mathrm{~g}$ powder compacts were pressed with a manual press in a $8 \mathrm{~mm}$ diameter cylindrical die. The compaction pressure was adjusted to achieve a relative green-density of $56 \%$.

Theoretical calculations of phase diagrams (CALPHAD) have demonstrated that for both nickel and iron binder, the 2 phase carbon window is narrowed in comparison with WC-Co [7]. In order to avoid the formation of free graphite and $\eta$ phase, the 2 phase carbon window is targeted during powder preparation in order to reach the 2 phase window after cooling (Fig. 2). Nevertheless, by contrast with the Co binder, the 2 phase \{WC+FCC-binder $\}$ domain is difficult to reach with iron or nickel binder as the $\{$ WC+liquid $\}$ high temperature 2 phase structure does not have the same carbon composition [8]. Alloy compositions are summarized in Tab. 1. Carbon was added to the initial mixtures to prevent decarburization during heating. In addition, a W-rich alloy lying in the $\left\{\mathrm{M}_{6} \mathrm{C}+\right.$ binder $\left.+\mathrm{WC}\right\} 3$ phase domain and a $\mathrm{C}$-rich alloy lying in the \{graphite+binder+WC 3 -phase domain were prepared for each binder to study the effect of carbon potential (Fig. 2) (Tab. 1).

Table 1. Composition and density measurements after a hot pressing treatment at $1410^{\circ} \mathrm{C}$ for $\mathrm{WC}$ Co and WC-Fe alloys and at $1450^{\circ} \mathrm{C}$ for WC-Ni alloys. 


\begin{tabular}{|c|c|c|c|c|c|c|c|}
\hline Alloys & Phase field & $\begin{array}{c}\text { W } \\
{[w t \%]}\end{array}$ & $\begin{array}{c}\mathrm{C} \\
{[\mathrm{wt} \%]}\end{array}$ & $\begin{array}{c}\text { Co } \\
{[w t \%]}\end{array}$ & $\begin{array}{c}\mathrm{Fe} \\
{[\mathrm{wt} \%]}\end{array}$ & $\begin{array}{c}\text { Ni } \\
{[w \mathbf{w} \%]}\end{array}$ & $\begin{array}{l}\text { Density } \\
{\left[\mathrm{g} / \mathrm{cm}^{3}\right]}\end{array}$ \\
\hline \multirow{3}{*}{ WC-Co } & 2 phase & 83.1 & 5.36 & 11.46 & $<0.01$ & $<0.001$ & 14.21 \\
\hline & 3 phase $\mathrm{W}$-rich & 83.1 & 5.22 & 11.2 & $<0.01$ & $<0.001$ & 14.51 \\
\hline & 3 phase C-rich & 82.6 & 5.6 & 11.71 & 0.019 & $<0.001$ & 14.19 \\
\hline \multirow{3}{*}{ WC-Ni } & 2 phase & 82.3 & 5.25 & 0.27 & $<0.1$ & 11.27 & 14.44 \\
\hline & 3 phase $W$-rich & 83.2 & 4.98 & $<0.2$ & $<0.1$ & 10.7 & 14.67 \\
\hline & 3 phase $\mathrm{C}$-rich & 82.1 & 5.49 & $<0.2$ & $<0.1$ & 11.6 & 14.22 \\
\hline \multirow{3}{*}{ WC-Fe } & 2 phase & 82.9 & 5.55 & 0.21 & 11 & $<0.1$ & 14.1 \\
\hline & 3 phase $W$-rich & 83.2 & 5.3 & 0.21 & 10.95 & $<0.1$ & 14.2 \\
\hline & 3 phase $\mathrm{C}$-rich & 82 & 5.93 & $<0.2$ & 11.58 & $<0.1$ & 13.72 \\
\hline
\end{tabular}

Thermogravimetric analyses (TGA) and dilatometry experiments were performed with a SETARAM ${ }^{\text {TM }}$ Setsys device and a SETARAMTM TMA-92 dilatometer, respectively. The same thermal cycle was applied for all experiments. The compact was first heated up to $400^{\circ} \mathrm{C}$ at $1{ }^{\circ} \mathrm{C} / \mathrm{min}$ under $\mathrm{He}-\mathrm{H}_{2}$ atmosphere and held for $1 \mathrm{~h}$ in order to remove the organic lubricant and reduce the binder oxides. Then the specimen was heated up to $1450^{\circ} \mathrm{C}$ at $3{ }^{\circ} \mathrm{C} / \mathrm{min}$ under $\mathrm{Ar}$, held during $30 \mathrm{~min}$ and finally cooled down with a cooling rate of $30^{\circ} \mathrm{C} / \mathrm{min}$. Shrinkage was deduced from the measured variation $\Delta h(t)$ of the compact height with respect to the initial height $h_{i}$ :

$$
\varepsilon=\left(\frac{\Delta h(t)}{h_{i}}\right) \times 100
$$

Densities of the alloys sintered at $1450^{\circ} \mathrm{C}$ were determined from mass and dimension measurements and relative densities were deduced by comparison with the values of the fully densified samples prepared by hot pressing (Tab. 1).
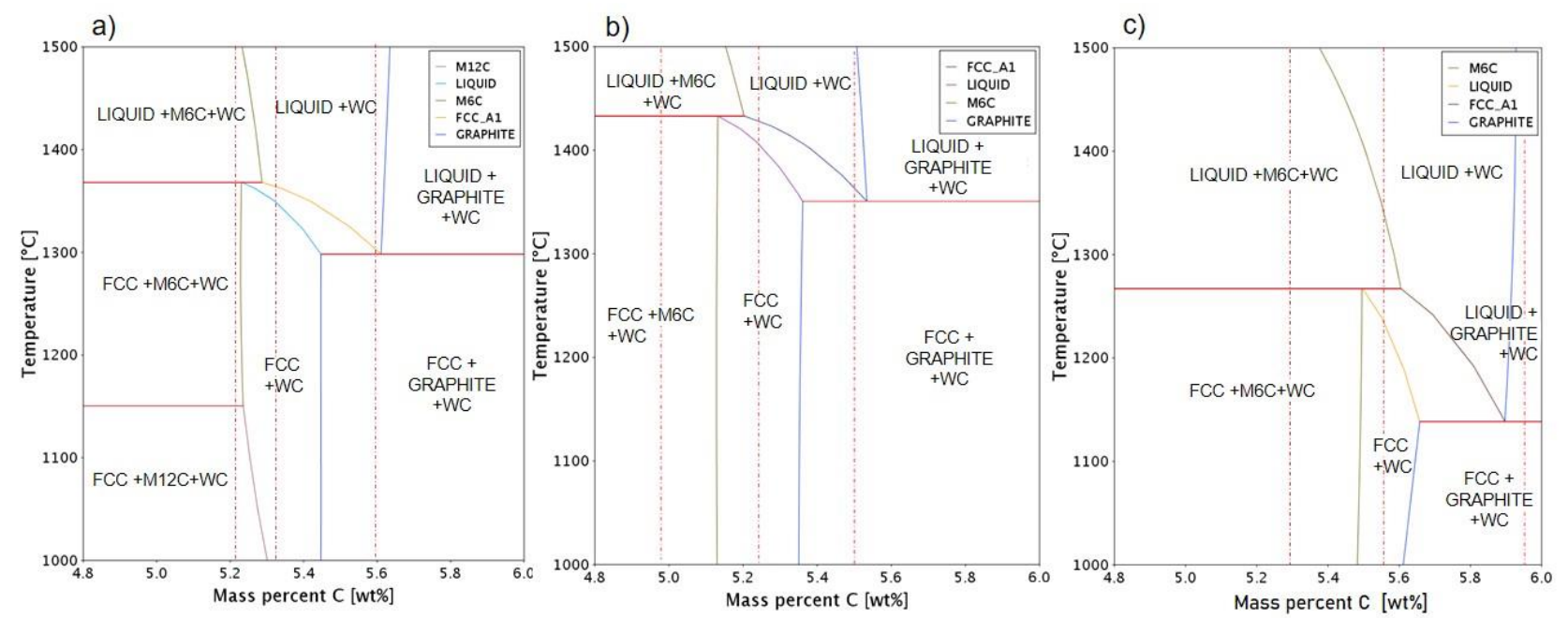

Fig. 2. Phase diagram for 20 vol $\%$ of a) cobalt binder, b) nickel binder and c) iron binder from Thermo-Calc ${ }^{\mathrm{TM}}$ database TCFE9. The red dot lines represent the composition of alloys of this study described in Tab.1. 
Interrupted dilatometric tests were done to characterize the microstructure with qualitative and quantitative analyses performed on partially sintered samples at $1150^{\circ} \mathrm{C}, 1280^{\circ} \mathrm{C}$ and $1320^{\circ} \mathrm{C}$. These temperatures were chosen to study the early stage of solid state sintering, the rearrangement step and the last stage of the solid state sintering.

Diamond wire was used to cut a vertical section of the specimen and the surface was prepared by subsequent polishing steps from $40 \mu \mathrm{m}$ to $1 \mu \mathrm{m}$ using diamond sheets. For the microstructure analysis, field emission scanning electron microscopy (FESEM) images were acquired using a Carl Zeiss Ultra 55 in the backscattered mode. The accelerating voltage was fixed at $10 \mathrm{kV}$ to limit the penetration depth of the electrons. To get statistical results for the quantitative analysis, a uniform sampling was done on sections, and ten $2048 \times 1536$ pixels pictures were taken at $\mathrm{x} 3000$ magnification. Intercept length distributions in WC and binder phases were determined on thresholded FESEM images using Aphelion software.

From the thresholded FESEM images, the area fraction $A_{A}(X)$ of phase $\mathrm{X}$ and the remaining area fraction $A_{A}\left(O_{l}(X)\right)$ after morphological opening with a linear segment of size $l$ can be measured. The area thus removed represents the area in which a linear segment of size smaller than $l$ can be included and its relative contribution corresponds to the cumulative size class $G(l)$ of size smaller than $l[19]$ :

$$
G(l)=\frac{A_{A}(X)-A_{A}\left(o_{l}(X)\right)}{A_{A}(X)}
$$

$G(l)$ is the area fraction or equivalently an estimate of the volume fraction [20] in which a linear intercept with length smaller than 1 can be included. The distribution density is the derivative of G: $g(l)=\frac{d G}{d l}$ where $\mathrm{g}(\mathrm{l}) \mathrm{dl}$ represents the area fraction or an estimate of the volume fraction of the $\mathrm{X}$ phase in which an intercept with length between 1 and $1+\mathrm{dl}$ length can be included. Since the total volume area is changing because of the shrinkage of the material, the volume fraction will be reported to the total solid volume, which remains unchanged:

$$
g^{\prime}(l)=\frac{d G}{d l} \frac{V_{V}(X)}{1-V_{V}(\text { pores })}
$$

$\mathrm{Vv}(\mathrm{X})$ is the volume of the $\mathrm{X}$ phase and $\mathrm{Vv}$ (pores) the volume of the pores. $\mathrm{g}^{\prime}(1)$ is then proportionnal to the actual volume of the $\mathrm{X}$ phase in the corresponding size class.

As the material is porous at the interrupted test temperatures, the pores volume fraction and the binder volume fraction in the solid volume were checked for consistency as in reference [21].

\section{Experimental results}

\subsection{Debinding and reduction of surface oxides}

According to the literature, the onset of solid state spreading of the metallic binder on WC grains and start of shrinkage is dependent on the reduction of the oxides at the surface of the powder particles [22,23]. The reduction temperature of the oxides present in the powder mixtures was determined by TGA experiments. Surface oxides are removed together with the organic lubricant in the $250-350^{\circ} \mathrm{C}$ temperature range for Co 
and Ni binder, whereas oxygen elimination is delayed to $650-700^{\circ} \mathrm{C}$ for the Fe binder as shown for the 2 phase alloys in Fig. 3. Similar results were obtained whatever the carbon content of the alloys. Chemical analyses with the $\mathrm{Fe}$ binder have shown a $0.32 \mathrm{wt} \%$ oxygen residue after debinding at $400^{\circ} \mathrm{C}$ and $<0.01 \mathrm{wt} \%$ after sintering.
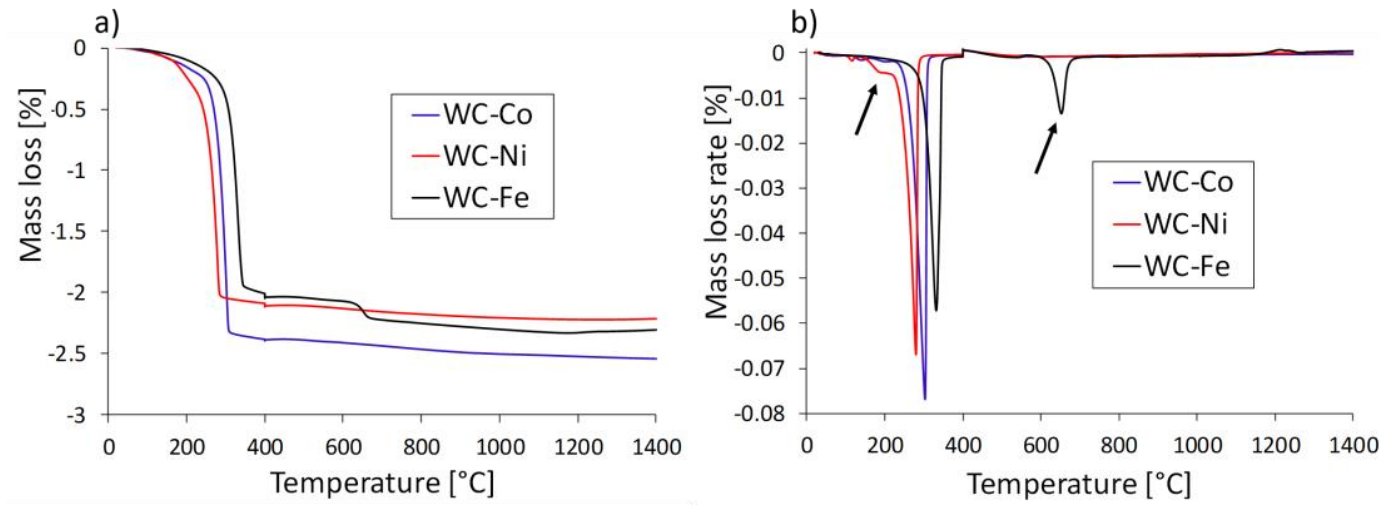

Fig. 3. Thermogravimetric plots of the 2 phase alloys: (a) mass loss and (b) mass loss rate. The large peaks in (b) correspond to the organic lubricant elimination and the arrows indicate the reduction step of the metallic binder oxides.

\subsection{Effect of $\mathrm{C}$ content on the shrinkage behaviour}

Previous investigations have pointed out the effect of carbon content on the densification behaviour of WCCo alloys [24] and are also observed in the present work (Fig. 4a). It is found that the shrinkage starts earlier in the W-rich alloy than in the C-rich one. Also, the liquid phase sintering stage starts later for the WC-Co Wrich alloy due to the higher liquidus temperature. The same behaviour is observed for the Ni binder (Fig. 4b). Especially, the difference in shrinkage onset is still more markedly observed than for Co binder. The liquid phase sintering occurs when the binder starts to melt and is characterized by a sharp drop of the shrinkage rate curves. For WC-Ni C-rich alloy, this sharp drop is preceded by an increase, which is attributed to the swelling of the material when crossing the 3 phase $\{$ WC+liquid+FCC-binder $\}$ domain.

The influence of $\mathrm{C}$ addition on the onset of shrinkage is also detected for Fe binder (Fig. 4c). However, its effect is reduced, due to the early formation of liquid in WC-Fe C-rich alloy. 


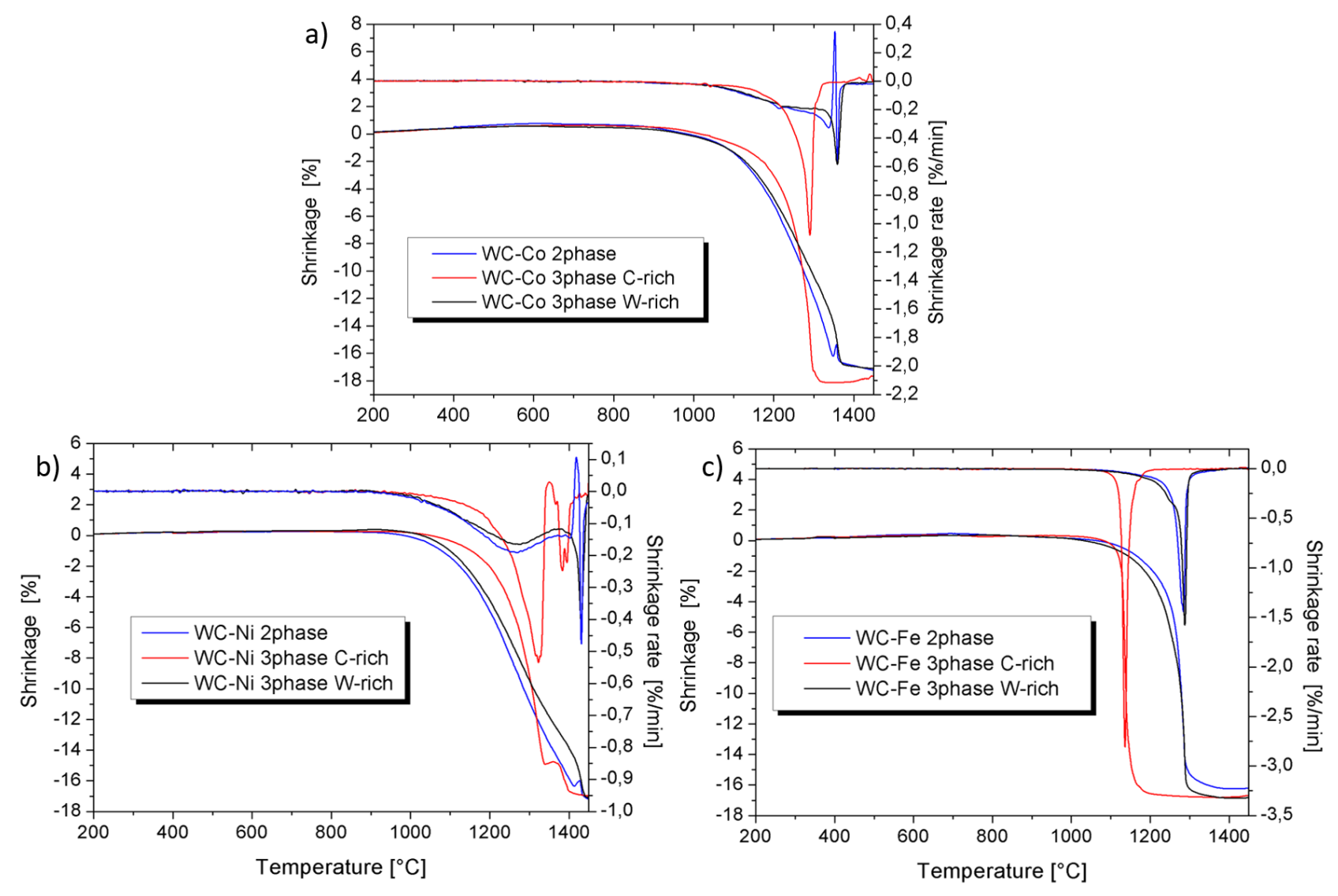

Fig. 4. a) Shrinkage and shrinkage rate curves for a) WC-Co alloys, b) WC-Ni alloys and c) WC-Fe alloys.

\subsection{Effect of the binder nature}

The influence of the binder nature on shrinkage of the material was compared. Linear shrinkage and shrinkage rate of the 2 phase alloys are plotted on Fig. 5.

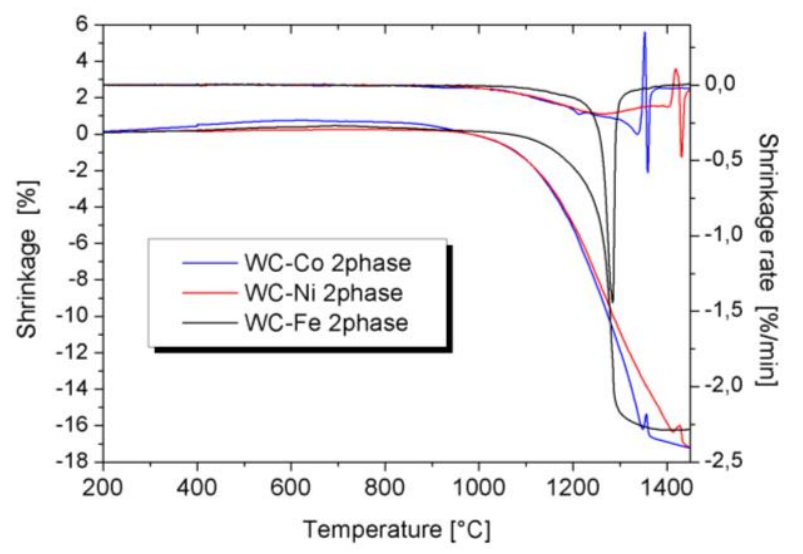

Fig. 5. Shrinkage and shrinkage rate curves for the 2 phase alloys.

Solid state sintering hardly occurs with WC-Fe alloy since little shrinkage is observed before the liquid formation (around $1240^{\circ} \mathrm{C}$ ). In comparison, WC-Co and WC-Ni begin to shrink in the solid state around 1000- 
$1100^{\circ} \mathrm{C}$. WC-Ni and WC-Co alloys have a similar shrinkage until about $1200^{\circ} \mathrm{C}$ where the shrinkage is enhanced in WC-Co. The onset of liquid phase sintering can be determined by the tangent method and is respectively $1250^{\circ} \mathrm{C}, 1340^{\circ} \mathrm{C}$ and $1410^{\circ} \mathrm{C}$ for WC-Fe, WC-Co and WC-Ni, in accordance with the solidus temperature on the phase diagrams (Fig. 2). For WC-Ni and WC-Co alloys, a swelling attributed to the crossing of the 3 phase $\{\mathrm{WC}+$ liquid+FCC-binder $\}$ domain is observed. Relative densities of the alloys after sintering at $1450^{\circ} \mathrm{C}$ are given in Tab. 2. The final densities are slightly lower for the Fe binder.

Table 2. Relative density of the 2 phase and 3 phase alloys after sintering at $1450^{\circ} \mathrm{C}$

\begin{tabular}{|c|c|c|c|c|c|c|c|c|c|}
\hline \multirow{3}{*}{ Samples } & \multicolumn{3}{|c|}{ WC-Co } & \multicolumn{3}{|c|}{ WC-Ni } & \multicolumn{3}{|c|}{ WC-Fe } \\
\hline & \multirow[t]{2}{*}{ 2-phase } & \multicolumn{2}{|c|}{ 3-phase } & \multirow[t]{2}{*}{ 2-phase } & \multicolumn{2}{|c|}{ 3-phase } & \multirow[t]{2}{*}{ 2-phase } & \multicolumn{2}{|c|}{ 3-phase } \\
\hline & & C-ric & W-rich & & C-ricl & W-rich & & C-rich & W-rich \\
\hline Density [\%] & 100 & 100 & 100 & 100 & 100 & 100 & 98.5 & 98.3 & 99 \\
\hline
\end{tabular}

\subsection{Microstructural evolution during solid state sintering}

Microstructures of the 2 phase WC-Fe, WC-Co and WC-Ni alloys are displayed after heating at $1150^{\circ} \mathrm{C}$, $1280^{\circ} \mathrm{C}$ and $1320^{\circ} \mathrm{C}$ in Fig. 6. For WC-Fe, the binder was solid only at $1150^{\circ} \mathrm{C}$. The distributions of the volume fraction of intercepts per unit solid volume for binder and pore phases at different temperatures are presented in Fig. 7.
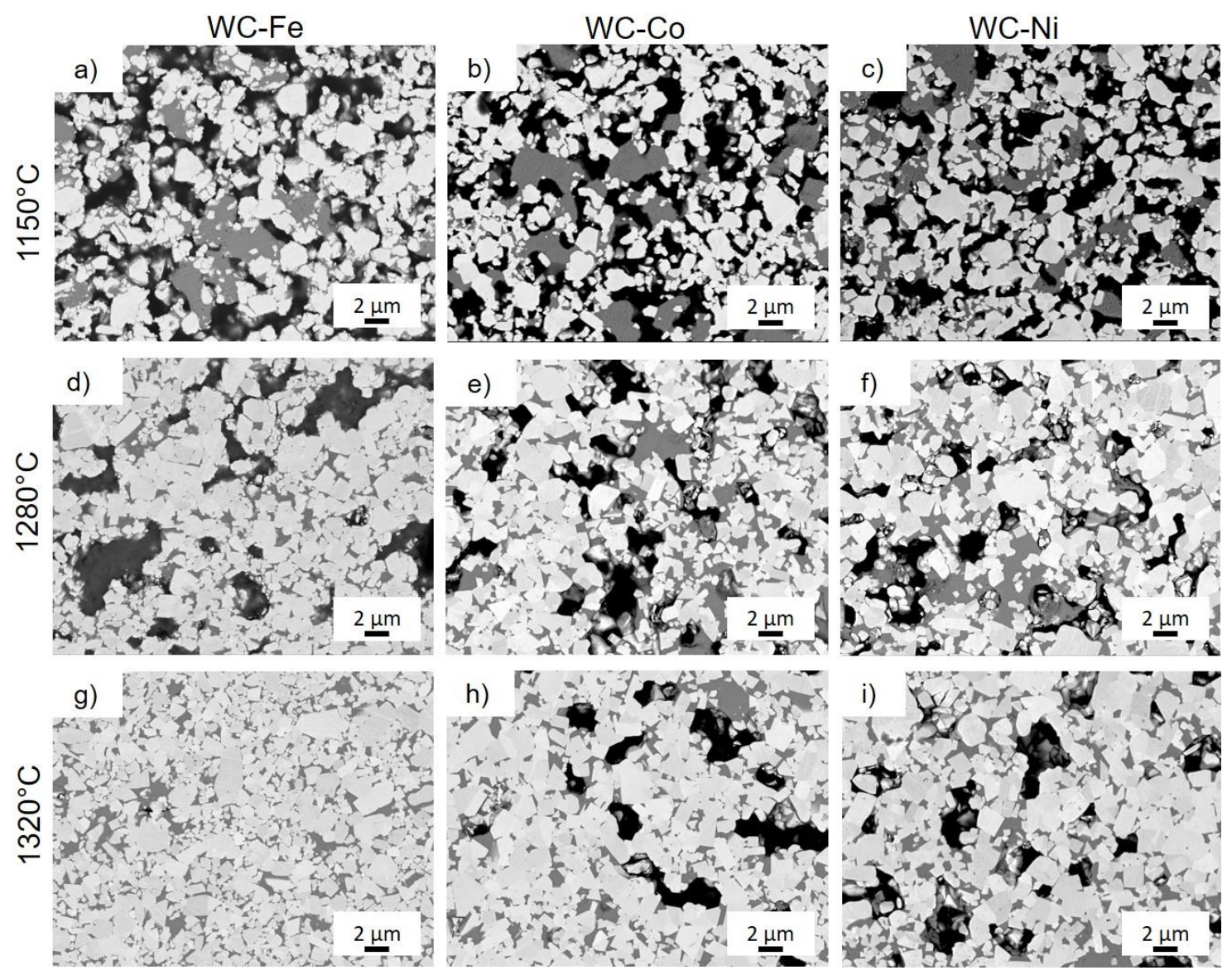
Fig. 6. Microstructures of the 2 phase alloys: WC-Fe sintered at a) $1150^{\circ} \mathrm{C}$, d) $1280^{\circ} \mathrm{C}$, g) $1320^{\circ} \mathrm{C}$, WC-Co sintered at b) $1150^{\circ} \mathrm{C}$, e) $1280^{\circ} \mathrm{C}$, h) $1320^{\circ} \mathrm{C}$ and WC-Ni sintered at c) $1150^{\circ} \mathrm{C}$, f) $1280^{\circ} \mathrm{C}$, i) $1320^{\circ} \mathrm{C}$.

From microstructure and image analysis study of WC-Co materials, the classical behaviour [24,25] of spreading of the large binder pools into smaller intergranular areas is observed between $1150^{\circ} \mathrm{C}$ and $1280^{\circ} \mathrm{C}$ (Fig. 6, Fig. 7a), with a strong reduction of the overall porosity (Fig. 7b).
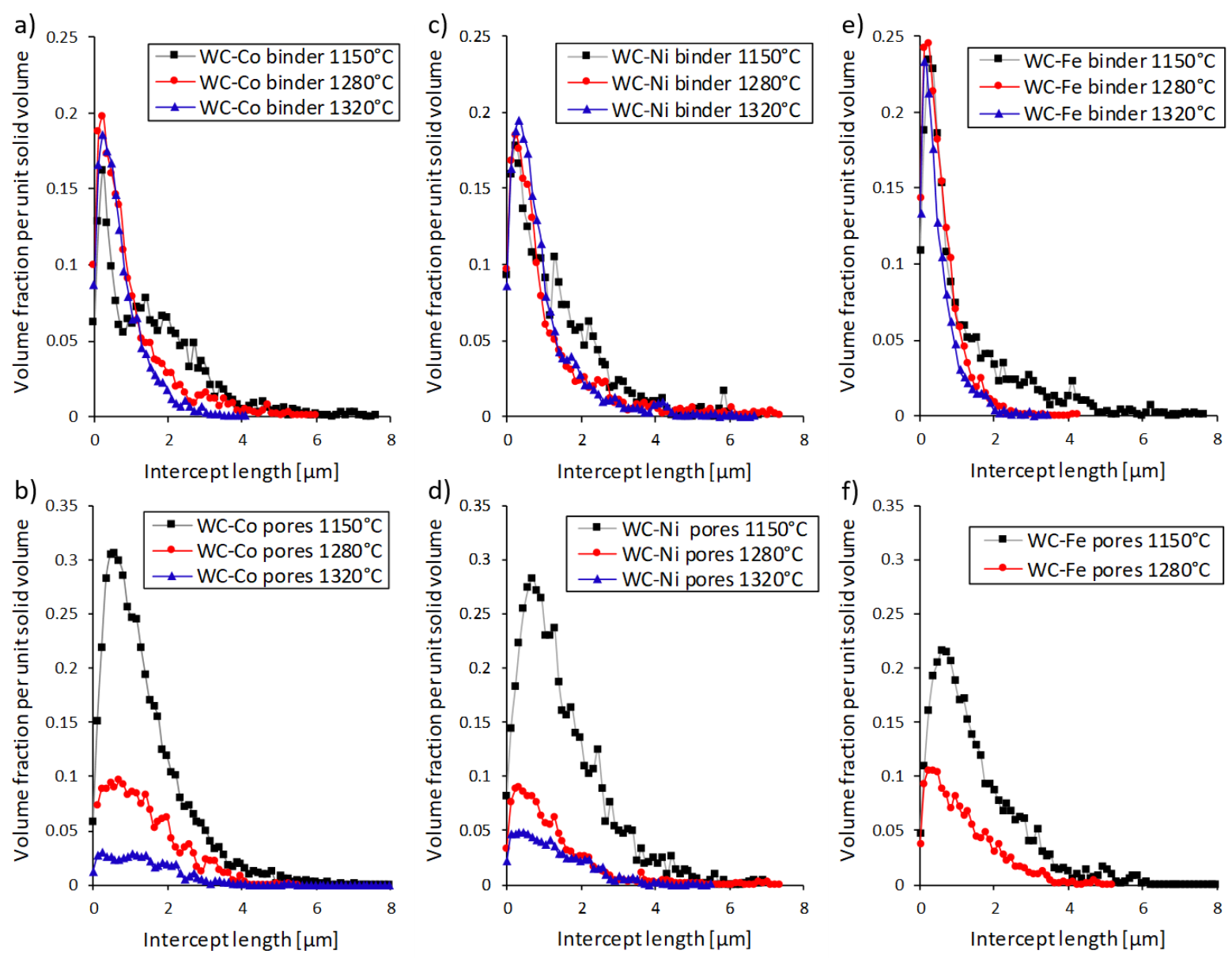

Fig. 7: Distributions of the volume fraction of intercepts per unit solid volume of the binder phase and pores phase for the 2 phase studied alloys as a function of the temperature: $(a, b) W C-C o,(c, d) W C-N i$ and $(e, f) W C-$ Fe.

The same trend is observed for WC-Ni alloy (the total volume fraction of binder is overevaluated at $1280^{\circ} \mathrm{C}$ and $1320^{\circ} \mathrm{C}$, due to the underestimation of the porosity for these alloys). The major difference is that more fine intergranular binder films are observed already at $1150^{\circ} \mathrm{C}$, as compared to WC-Co (Fig. 6c,7c). This may be due to the difference between $\mathrm{Ni}$ and Co powder morphology or to a better 'crushing' of Ni ligaments between WC particles during the milling step. Moreover, spreading of the binder into intergranular areas is not so efficient for WC-Ni alloys at high temperature compared to WC-Co alloys and large pores persist at higher temperature (Fig. 7d). 
For WC-Fe, large binder pools and large pores are observed at $1150^{\circ} \mathrm{C}$ (Fig. 7e,f). At $1280^{\circ} \mathrm{C}$, the binder has spread into the porous microstructure, since the liquid is present for this composition at this temperature (Fig. 2). No porosity is detected after liquid phase sintering of WC-Fe materials at $1320^{\circ} \mathrm{C}$.

\section{Discussion}

The shrinkage behaviour during sintering can be directly linked to the microstructure evolution, especially to the binder spreading into the intergranular porosity. Dilatometry and SEM analysis can provide information about the influence of the binder nature on the shrinkage and microstructure of cemented carbides.

The microstructural observations are in accordance with shrinkage results, with a similar shrinkage for WCCo and WC-Ni from $1000^{\circ} \mathrm{C}$ to $1200^{\circ} \mathrm{C}$, which can be attributed to the spreading of the binder into the small porosity, inducing WC particle rearrangement [3]. The lower spreading efficiency of the binder for WC-Ni alloys at higher temperature may be correlated to the lower shrinkage rate compared to WC-Co alloys. This lower spreading efficiency at higher temperature may be due to the higher amount of fine pores which are already filled at the beginning of solid state sintering by fine intergranular binder films. As a consequence, the binder essentially spreads into the bigger porosity, which slows down the shrinkage rate from around 1200$1250^{\circ} \mathrm{C}$ in comparison to WC-Co alloys. The higher ductility of nickel metal in comparison to Co and $\mathrm{Fe}$ metals could explain the formation of these intergranular binder films during milling for WC-Ni in comparison to WC-Co and WC-Fe alloys.

The delayed shrinkage for WC-Fe alloys is explained by the difficulty of the binder to spread on WC grains and fill the intergranular porosity. As observed on the microstructure in that case, big spheroidal binder clusters already present in the material at the beginning of the shrinkage remain until the apparition of the liquid. Compared to $\mathrm{Ni}$ and $\mathrm{Co}$, these binder clusters do not form bridges between WC grains, and exhibit a convex shape, probably due to a larger wetting angle of the binder with the WC grains (Fig. 8). This also explains the lower density of these samples. 


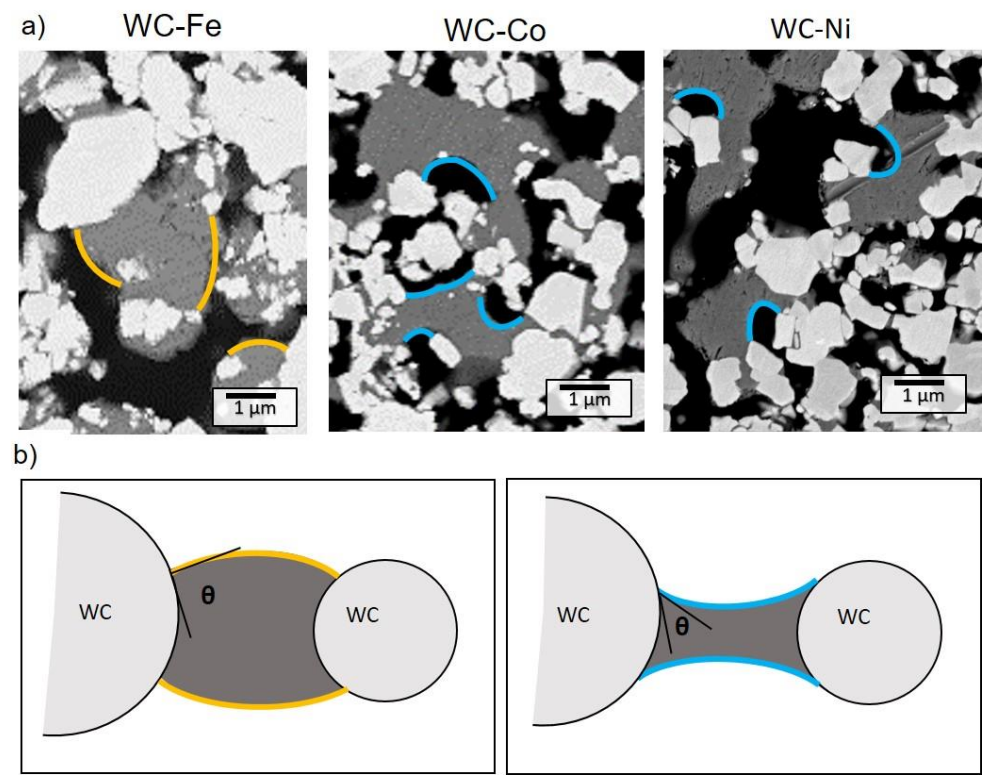

Fig. 8. a) Microstructure of WC-M (M=Fe, Co and Ni) 2 phase alloys sintered at $1150^{\circ} \mathrm{C}$. b) Schematic illustrating the wetting angle between WC grains and binder grains.

For Fe, liquid phase sintering then starts whereas the binder has not spread into the porosity, and induces a very fast shrinkage, as observed on dilatometric curves (Fig. 4).

The bad spreading at the early stage of solid state sintering in the case of WC-Fe alloys may be due to a coarser initial iron raw powder or to a chemical effect of the iron binder itself on the interfacial energy or diffusion coefficient. Microstructural observations and image analysis results however show that binder pools have similar sizes at $1150^{\circ} \mathrm{C}$. From these results, it can be concluded that it is most probably the chemical nature of the binder which is responsible for the delayed shrinkage with iron binder. Indeed, the convex shape of binder pools indicates a bad wetting between WC and the iron binder phase, which could be responsible for the bad spreading of the iron binder into the porosity.

Regarding the densification mechanisms, from dilatometric and microstructural investigations, particle rearrangement induced by spreading of the binder is considered as the main densification mechanism during solid state sintering of cemented carbides. Spreading is enhanced for a binder with a lower surface energy and interface energy with WC, both of which depend on the chemical nature of the binder. From DFT calculation of surface/interface energies [26], binder spreading should be slightly promoted on the WC surface and into WC/WC grain boundaries for Ni alloys rather than Co and even more than Fe.

In addition, the shrinkage kinetics associated to the binder spreading into the porosity can be quantified from a previous model [25]. Mass transport is assumed to be controlled by volume diffusion from the binder phase to the pores. Calculation is done by using a general representation of the geometry including stereological parameters of the microstructure. Assuming a perfect wetting of WC grains by the solid binder, the shrinkage rate is expressed as:

$$
\dot{\varepsilon}=\frac{8 D_{V} \gamma \Omega}{R T} G(D)
$$


where $D_{V}$ is the average volume self-diffusion coefficient in the binder, $\gamma$ is the surface energy, $\Omega$ the molar volume of the binder, $\mathrm{R}$ the gas constant and $T$ the temperature. $G(D)$ is a function of the microstructure which varies with the density $D$ and which scales with the inverse of the cube of WC particle size. As a first approximation, by taking a scaling factor equal to 1 and a particle size of $1 \mu \mathrm{m}$ and by neglecting the C/W effect, an order of magnitude of the shrinkage rate can be obtained. The results are summarized for a calculation at $1100^{\circ} \mathrm{C}$ for the 3 binders (Tab. 3). Experimental shrinkage rates can be estimated from the dilatometric results and are summarized in Tab. 3 .

Table3. Physical parameters of the different binders and approximate calculation and experimental values of the shrinkage rate at $1100^{\circ} \mathrm{C}$, resulting from solid state spreading of the binder with a WC particle size of 1 $\mu \mathrm{m}$.

\begin{tabular}{|c|c|c|c|c|c|}
\hline Binder & $\boldsymbol{D}_{V}\left[\mathbf{m}^{2} \mathbf{s}^{-\mathbf{1}}\right][\mathbf{2 7}]$ & $\gamma\left[\mathbf{J} . \mathbf{m}^{-2}\right][\mathbf{2 8}]$ & $\mathbf{\Omega}\left[\mathbf{m}^{3}\right]$ & $\dot{\varepsilon}_{\text {th }}\left[\mathrm{s}^{-\mathbf{1}}\right]$ & $\dot{\boldsymbol{\varepsilon}}_{\text {exp }}\left[\mathrm{s}^{-\mathbf{1}}\right]$ \\
\hline $\mathbf{F e}$ & $1.910^{-15}$ & 2.1 & $7.1410^{-6}$ & $2.010^{-5}$ & $\approx 1.10^{-6}$ \\
\hline $\mathbf{C o}$ & $2.710^{-15}$ & 2.3 & $6.7010^{-6}$ & $2.910^{-5}$ & $\approx 2.10^{-5}$ \\
\hline $\mathbf{N i}$ & $1.610^{-15}$ & 2.4 & $6.5810^{-6}$ & $1.810^{-5}$ & $\approx 2.10^{-5}$ \\
\hline
\end{tabular}

For WC-Co and WC-Ni alloys, experimental solid state sintering kinetics are then consistent with a mechanism of spreading of the binder into the pores controlled by volume diffusion, whereas an additional effect seems to limit the kinetics for WC-Fe alloys at low temperature. Since the model assumes a perfect wetting of WC grains by the binder, limitation could come from a larger value of the metal surface energy and/or of the phase boundary energy with WC. The curvature of the binder surface would then be larger or the surface could even become convex, slowing down or even impeding spreading of the binder into the porosity. This assumption is confirmed by the microstructural observations, showing a large wetting angle at the interface between Fe and WC and a convex binder surface with the WC grains.

\section{Conclusion}

Investigations of shrinkage behaviour and microstructure have been done in order to characterize the sintering of cemented carbides with alternative binders. Dilatometric experiments have shown distinct behaviours depending on the binder nature. While WC-Fe hardly shows any solid state sintering, WC-Co and WC-Ni have a similar shrinkage until $1200^{\circ} \mathrm{C}$ whereas WC-Co shrinkage is more important above this temperature.

From shrinkage results correlated with microstructural observations and quantitative analyses on interrupted tests, it has been concluded that the good shrinkage of WC-Ni and WC-Co until $1200^{\circ} \mathrm{C}$ is due to the efficient spreading of the binder into the small porosity. The lower spreading efficiency and shrinkage of WC-Ni at higher temperature compared to WC-Co is probably due to the lower amount of remaining fine pores. For WC- 
Fe alloys, the delayed shrinkage could be attributed to the bad spreading of the binder, probably due to the high surface and/or interface energy with WC.

To summarize, in case of a good wetting of WC grains by the binder phase, solid state sintering of cemented carbides is mainly driven by spreading of the solid binder into the intergranular porosity, with mass transport controlled by volume diffusion in the binder, as observed with Co or Ni. Densification is impeded or delayed until liquid phase sintering in case of bad wetting properties of the binder, as observed with Fe, and the final density is also smaller in this case. This is a limitation for the use of $\mathrm{Fe}$ as a substitute for Co, in addition to the sensitivity to corrosion. As for WC-Ni alloys, densification is similar to WC-Co alloys but mechanical properties are known to be not so good [29]. Therefore, Co-Ni-Fe alloys with possibly other minor elements would probably be the best candidates for substitution of Co in cemented carbides.

Acknowledgment

The authors are grateful to Sandvik \& Coromant R\&D, Stockholm, Sandvik Mining, R\&D Rock Tools, Stockholm and Seco Tools AB, Fagersta, Sweden for their technical support, for provision of powder mixtures and for fruitful discussions about experimental results.

\section{References}

[1] H. M. Ortner, P. Ettmayer, H. Kolaska, and I. Smid, "The history of the technological progress of hardmetals". Int. J. Refract. Met. Hard Mater., vol. 49, no. 1, pp. 3-8, 2015.

[2] G. . Upadhyaya, "Materials science of cemented carbides - an overview". Mater. Des., vol. 22, no. 6, pp. 483-489, 2001.

[3] A. G. P. da Silva, W. D. Schubert, and B. Lux, "The role of the binder phase in the WC-Co sintering". Mater. Res., vol. 4, no. 2, pp. 59-62, 2001.

[4] REACH European Regulation available at: https://ec.europa.eu/growth/sectors/chemicals/reach en

[5] A.H. Tkaczyk, A. Bartl, A. Amato, V. Lapkovskis, M. Petranikova, "Sustainability evaluation of essential critical raw materials: cobalt, niobium, tungsten and rare earth elements". J. Physics D: Applied Physics, vol. 51, pp. 203001, 2018.

[6] E. Holmström, R. Lizárraga, D. Linder, A. Salmasi, W. Wang, B. Kaplan et al., "High entropy alloys: Substituting for cobalt in cutting edge technology”. Appl. Mater. Today, vol. 12, pp. 322-329, 2018.

[7] C. M. Fernandes and A. M. R. Senos, "Cemented carbide phase diagrams: A review". Int. J. Refract. Met. Hard Mater., vol. 29, no. 4, pp. 405-418, 2011.

[8] B. Uhrenius, H. Pastor, and E. Pauty, "On the composition of Fe-Ni-Co-WC-based cemented carbides". Int. J. Refract. Met. Hard Mater., vol. 15, no. 1-3, pp. 139-149, 1997. 
[9] W. D. Schubert, M. Fugger, B. Wittmann, and R. Useldinger, "Aspects of sintering of cemented carbides with Fe-based binders". Int. J. Refract. Met. Hard Mater., vol. 49, no. 1, pp. 110-123, 2015.

[10] J. M. Guilemany, I. Sanchiz, B. G. Mellor, N. Llorca, and J. R. Miguel, "Mechanical-property relationships of $\mathrm{Co} / \mathrm{WC}$ and $\mathrm{CoNiFe} / \mathrm{WC}$ hard metal alloys". Int. J. Refract. Met. Hard Mater., vol. 12, no. 4, pp. 199-206, 1993.

[11] C. Liu, “Alternative Binder Phases for WC Cemented Carbides”. KTH Royal Institute of Technology, 2015.

[12] Y. Gao, B. H. Luo, K. J. He, W. W. Zhang, and Z. H. Bai, "Effect of Fe/Ni ratio on the microstructure and properties of WC-Fe-Ni-Co cemented carbides". Ceram. Int., vol. 44, no. 2, pp. 2030-2041, 2018.

[13] B. Wittmann, W. D. Schubert, and B. Lux, "WC grain growth and grain growth inhibition in nickel and iron binder hardmetals". Int. J. Refract. Met. Hard Mater., vol. 20, no. 1, pp. 51-60, 2002.

[14] M. De Nicolás, H. Besharatloo, P. Alvaredo, J. J. Roa, L. Llanes, and E. Gordo, "Design of alternative binders for hard materials". Int. J. Refract. Metals Hard Mater., vol. 87, p. 105089, 2020.

[15] J. Long, Z. Zhang, T. Xu, and B. Lu, "Microstructure, mechanical properties and fracture behavior of WC-40vol.\% Ni3Al composites with various carbon contents". Int. J. Refract. Met. Hard Mater., vol. 40, pp. 2-7, 2013.

[16] J. J. Pittari, H.A. Murdoch, S.M. Kilczewski, B.C. Hornbuckle, J.J. Swab, K.A. Darling, et al., "Sintering of tungsten carbide cermets with an iron-based ternary alloy binder: Processing and thermodynamic considerations". Int. J. Refract. Met. Hard Mater., vol. 76, pp. 1-11, 2018.

[17] A. Petersson and J. Ågren, "Modelling WC-Co sintering shrinkage-Effect of carbide grain size and cobalt content." Mater. Sci. Eng. A, vol. 452-453, pp. 37-45, 2007.

[18] S. Lay and J.-M. Missiaen, Comprehensive Hard Materials- Hardmetals Ceramics Super Hard Materials-1.03 Microstructure and Morphology of Hardmetals, Elsevier. 2014.

[19] V. Chabretou, C. H. Allibert, and J. M. Missiaen, "Quantitative analysis of the effect of the binder phase composition on grain growth in WC-Co sintered materials". J. Mater. Sci., vol. 38, no. 12, pp. 2581-2590, 2003.

[20 ] R.T. DeHoff, and F.N. Rhines, "Quantitative Microscopy”. Mc Graw Hill. New York, 1968.

[21] V. Bounhoure, S. Lay, F. Charlot, A. Antoni-Zdziobek, E. Pauty, and J. M. Missiaen, "Effect of C content on the microstructure evolution during early solid state sintering of WC-Co alloys". Int. J. Refract. Met. Hard Mater., vol. 44, pp. 27-34, 2014.

[22] G. Leitner, K. Jaenicke-Rössler, C. Wagner, "Process during dewaxing and sintering of hardmetals". International conference on advances in hard materials production. Bonn: EPMA; 1992. Paper 13, pp. $1-10$. 
[23] J. Angseryd, M. Zwinkels, "Study of the chemical reactions during debinding of cemented carbide". Sintering'05: 4th International Conference on Science, Technology and Applications of Sintering, Grenoble, France, D. Bouvard and F. Valdivieso Editors, INPG, 2005. pp. 327-30.

[24] V. Bounhoure, J. M. Missiaen, S. Lay, and E. Pauty, "Discussion of nonconventional effects in solidstate sintering of cemented carbides”. J. Am. Ceram. Soc., vol. 92, no. 7, pp. 1396-1402, 2009.

[25] J.-M. Missiaen and S. Roure, "A general morphological approach of sintering kinetics: application to WC-Co solid phase sintering”. Acta Mater., vol. 46, no. 11, pp. 3985-3993, 1998.

[26] E. Fransson, M. A. Gren, and G. Wahnström, "A computational study of thin films in WC-Co cemented carbides: Vacancies and vibrations". in ICSHM11 Proceedings, Khao Lak, Thailand, 2019, pp. 57-58.

[27] P. Guiraldenq, "Diffusion dans les métaux". Techniques de l'ingénieur -Matériaux | Étude et propriétés des métaux, vol. 33, 1994.

[28] N. Eustathopoulos, M.G.Nicholas and B. Drevet, Wettability at High Temperatures, Pergamon, Elsevier Science Ltd, Oxford, UK, 1999.

[29] J. García, V. Collado Ciprés, A. Blomqvist, B. Kaplan. "Cemented carbide microstructures: a review”. Int. J. Refract. Met. Hard Mater., vol. 80, pp. 40-68. 2019. 